\title{
Impact of heavy proteinuria on clinical outcomes in patients on incident peritoneal dialysis
}

\author{
Seok Hui Kang, Kyu Hyang Cho, Jong Won Park, Kyung Woo Yoon and Jun Young Do*
}

\begin{abstract}
Background: There are few reports on the nutritional status changes and residual renal function (RRF) according to proteinuria levels in patients on peritoneal dialysis (PD).

Methods: A total of 388 patients on PD were enrolled. The patients were divided into 3 groups with respect to initial proteinuria: the $A(n=119 ;<500 \mathrm{mg} /$ day), $B(n=218 ; 500-3,500 \mathrm{mg} /$ day), and $C$ groups ( $\mathrm{n}=51 ;>3,500 \mathrm{mg} /$ day).

Results: The patients with higher proteinuria levels had a higher incidence of male sex, diabetes mellitus, and icodextrin use than those with lower proteinuria levels. Although initial peritoneal albumin loss in C group was lower than that detected in the other groups, no significant difference was observed in peritoneal albumin loss among the 3 groups at the end of follow-up period. At the time of PD initiation, the Geriatric nutritional risk index (GNRI) was lower in the $\mathrm{C}$ group than in the other 2 groups. However, at the end of the follow-up period, there was no significant difference in GNRI between the 3 groups. The GNRI increased, and the proteinuria level or RRF decreased more in the $\mathrm{C}$ group than in the other 2 groups. There were no significant differences in lean mass index or fat mass index change from the time of PD initiation to the end of the follow-up period. However, fat mass index and nPNA showed greater increases in the $C$ group. The multivariate analysis revealed that proteinuria was negatively correlated with GNRI at the time of PD initiation and at the end of the follow-up period. The initial RRF and proteinuria were negatively correlated with the RRF decline during the follow-up.
\end{abstract}

Conclusion: The attenuation of the nephrotic proteinuria, along with the RRF decline, was associated with the improvement of the malnutrition.

Keywords: Peritoneal dialysis, Proteinuria, Residual renal function, Nutrition

\section{Background}

Proteinuria is a widely known marker for glomerular/ tubulointerstitial disease, with increasing amounts of urinary protein reflecting a greater intensity of kidney injury [1]. Protein losses in the urine are usually compensated for by increased albumin synthesis in patients on peritoneal dialysis (PD) [2]. If protein loss exceeds protein synthesis, malnutrition develops. In addition, proteinuria has been shown to play direct and indirect roles in the deterioration of renal function [1].

Residual renal function (RRF) has consistently been a prognostic factor in patients on PD [3-5]. RRF has been associated with multiple beneficial effects, including

\footnotetext{
* Correspondence: jydo@med.yu.ac.kr

Department of Internal Medicine, Division of Nephrology, Yeungnam

University Hospital, 317-1 Daemyung-Dong, Nam-Ku 705-717, Daegu, Korea
}

blood pressure control, increased sodium concentration or fluid removal, increased middle molecule clearance, and better nutritional status [6]. RRF loss is associated with malnutrition via increased energy expenditure and poorer appetite.

Jansen et al. showed that greater urinary protein loss is a risk factor of rapid RRF decline in patients on dialysis [7]. High proteinuria levels in patients on PD are associated with malnutrition and a rapid RRF decline. Over time, patients on PD with high proteinuria levels develop a rapid RRF decline, but their degrees of malnutrition may be improved owing to decreased renal protein loss by the RRF reduction. However, there are few reports on the nutritional status changes and RRF according to proteinuria levels in patients on PD.

\section{Biomed Central}




\section{Methods}

\section{Selection of patients}

We reviewed the medical records at the Yeungnam University Hospital in Korea and identified 566 patients (>18 years of age) who received PD between January 1997 and May 2011. We excluded 57 patients who had initial oliguria (urine output $<200 \mathrm{~mL} /$ day), 97 patients for whom data on nutritional status or proteinuria levels were unavailable, and 24 patients with less than 1 year of follow-up. A total of 388 patients were enrolled in the study. The patients were divided into 3 groups with respect to initial proteinuria level: the A ( $\mathrm{n}=119$; $<500 \mathrm{mg} /$ day $), B(\mathrm{n}=218 ; 500-3,500 \mathrm{mg} /$ day $)$, and $\mathrm{C}$ groups $(\mathrm{n}=51,>3,500 \mathrm{mg} /$ day). This study was approved by the institutional review board of Yeungnam University Hospital (YUH-12-0366-O35). The board waived the need for informed consent.

\section{Clinical information}

The clinical and laboratory data collected at the time of PD initiation included age, sex, underlying disease of end-stage renal disease (ESRD), use of icodextrin or renin-angiotensin (RAS) blockade, mean arterial pressure (MAP; $\mathrm{mmHg}$ ), peritoneal equilibration test (PET), serum creatinine level $(\mathrm{mg} / \mathrm{dL})$, corrected calcium level $(\mathrm{mg} / \mathrm{dL})$, phosphorus level $(\mathrm{mg} / \mathrm{dL})$, C-reactive protein level (CRP; mg/dL), serum albumin level (g/dL), 24-hr urine volume (mL/day), $\mathrm{RRF}\left(\mathrm{mL} / \mathrm{min} / 1.73 \mathrm{~m}^{2}\right)$, weekly $K t / V$, peritoneal $K t / V$, Geriatric nutritional risk index (GNRI), dialysis modality (automated PD), 24-hr peritoneal albumin loss (mg/day), 24-hr proteinuria level (mg/day), 24-hr dialysate glucose absorption (g/day), lean mass index $\left(\mathrm{kg} / \mathrm{m}^{2}\right)$, and fat mass index $\left(\mathrm{kg} / \mathrm{m}^{2}\right)$.

The laboratory findings were measured every 6 months after the initiation of PD during the first year. The presence of peritonitis was documented from patient records during the first year. All patients with peritonitis were treated with cefazolin sodium and tobramycin sulfate as first-line antibiotics. For PET, the intra-abdominal fluid was drained, and PD fluid containing $4.25 \%$ glucose was infused intraperitoneally [8]. The creatinine level of the drained dialysate 4 hours after the injection was divided by that of blood to obtain the $\mathrm{D} / \mathrm{P} \mathrm{Cr}$ ratio. High transporter was defined as more than 0.81 of $\mathrm{D} / \mathrm{P} \mathrm{Cr}$ ratio. Weekly $K t / V$ was calculated using a 24-hr collection of dialysate and urine. The distribution of volume of urea was calculated with $\mathrm{V}$, estimated from the previous study [9]. Inadequate dialysis was defined as weekly $K t / V<1.7$. Dietary protein intake was calculated using the following equation: protein equivalent of nitrogen appearance $($ PNA $)=15.1+0.195$ urea appearance $(\mathrm{mmol} /$ day $)+$ protein losses (g/day) [10]. Urea appearance rate and protein losses were determined from the measured urea and protein excretion in the dialysate and urine. PNA was normalized for ideal body weight calculated using Lorenz equations [11]. Corrected calcium level was calculated on the basis of Payne's formula as follows: corrected calcium $(\mathrm{mg} / \mathrm{dL})=$ total calcium $(\mathrm{mg} / \mathrm{dL})+$ $0.8 \times[4-$ albumin $(\mathrm{g} / \mathrm{dL})]$ [12]. Peritoneal albumin loss (mg/day), proteinuria level ( $\mathrm{mg} /$ day), urine volume, and RRF were measured via the 24-hr urine and dialysate collection. The RRF was calculated from the 24-hr urine sample collection as the mean of the renal creatinine and urea clearances. The GNRI was calculated based on the serum albumin level and body weight, using the following equation: GNRI $=[1.489 \times$ albumin $(\mathrm{g} / \mathrm{L})]+[41.7 \times$ (body weight / ideal body weight)] [13,14]. The ideal body weight was calculated using the Lorentz equations [11]. The ratio of body weight to the ideal body weight was set at 1 when the body weight exceeded the ideal body weight $[13,15]$. Lean and fat masses were measured using dual X-ray absorptiometry (Hologic, Bedford, MA, USA). The fat and lean mass indexes were calculated by dividing the mass by the height squared. MAP was calculated using the following formula: $(2 \times$ systolic blood pressure + diastolic pressure)/3.

\section{Statistical methods}

The data were analyzed using SPSS version 19 (SPSS, Chicago, IL, USA). The distribution of the continuous variables was checked using the Kolmogorov-Smirnov test. The normally distributed variables were expressed as mean (SD) and compared using a $t$ test or one-way analysis of variance (ANOVA). The nonparametric variables were expressed as median (range) and were compared using the Mann-Whitney or Kruskal-Wallis test. One-way ANOVA or Kruskal-Wallis test were followed by a post hoc Tukey comparison or Bonferroni correction. The categorical variables were expressed as counts and percentages and analyzed using the Pearson $\chi^{2}$ or Fisher exact test. Correlation analysis was performed to assess the strength of the relationship between two continuous variables. Univariate followed by multivariate linear regression was used to determine the independent predictors of the RRF decline. Values of $P<0.05$ were considered statistically significant.

\section{Results}

Clinical characteristics at the time of PD initiation and the end of the follow-up period

The mean patient age was $53.3 \pm 14.5$ years in the $\mathrm{A}$ group, $53.3 \pm 13.3$ years in the $\mathrm{B}$ group, and $50.3 \pm 12.6$ years in the $C$ group $(P=0.323$; Table 1$)$. The patients with the higher proteinuria levels had a higher incidence of male sex, diabetes mellitus (DM), and icodextrin use than those with lower proteinuria levels. At the time of PD initiation, the GNRI in the $C$ group was lower than 
Table 1 Comparison of the clinical characteristics according to the initial proteinuria level at the time of peritoneal dialysis (PD) initiation and the end of the follow-up period

\begin{tabular}{|c|c|c|c|c|}
\hline At the time of PD initiation & A group ( $n=119)$ & B group $(n=218)$ & $C$ group $(n=51)$ & $P$ value* \\
\hline Age (years) & $53.3 \pm 14.5$ & $53.3 \pm 13.3$ & $50.3 \pm 12.6$ & 0.323 \\
\hline Sex (male) & $55(46.2 \%)$ & $123(56.4 \%)$ & $36(70.6 \%)$ & 0.012 \\
\hline Underlying disease & & & & $<0.001$ \\
\hline DM & $34(28.6 \%)$ & $120(55.0 \%)$ & $39(76.5 \%)$ & \\
\hline Hypertension & $45(37.8 \%)$ & $49(22.5 \%)$ & $4(7.8 \%)$ & \\
\hline Chronic glomerulonephritis & $9(7.5 \%)$ & $18(8.3 \%)$ & $7(13.7 \%)$ & \\
\hline Others & $12(10.1 \%)$ & $13(5.9 \%)$ & $1(2.0 \%)$ & \\
\hline Unknown & $19(16.0 \%)$ & $18(8.3 \%)$ & 0 & \\
\hline Use of icodextrin & $28(23.5 \%)$ & $72(33.0 \%)$ & $24(47.1 \%)$ & 0.009 \\
\hline Use of renin-angiotensin blockade & $101(84.9 \%)$ & $171(78.4 \%)$ & $46(90.2 \%)$ & 0.089 \\
\hline Creatinine level (mg/dL) & $6.78 \pm 2.54$ & $6.80 \pm 2.38$ & $6.94 \pm 2.88$ & 0.923 \\
\hline Corrected calcium level (mg/dL) & $9.05 \pm 0.87$ & $8.88 \pm 0.79$ & $8.93 \pm 0.84$ & 0.201 \\
\hline Phosphorus level (mg/dL) & $3.85 \pm 1.28$ & $3.79 \pm 1.16$ & $4.05 \pm 1.29$ & 0.364 \\
\hline CRP level (mg/dL) & $0.177(0.00 \sim 4.52)$ & $0.13(0.00 \sim 4.44)$ & $0.13(0.02 \sim 3.28)$ & 0.186 \\
\hline Dialysis modality (APD) & $2(1.7 \%)$ & $29(13.3 \%)$ & $6(11.8 \%)$ & 0.002 \\
\hline$\overline{\mathrm{PET}}$ & & & & 0.669 \\
\hline High transporter & $17(14.3 \%)$ & $30(13.8 \%)$ & $7(13.7 \%)$ & \\
\hline Others & $99(83.2 \%)$ & $186(85.3 \%)$ & $44(86.3 \%)$ & \\
\hline NA & $3(2.5 \%)$ & $2(0.9 \%)$ & $0(0 \%)$ & \\
\hline Weekly KtN & $2.44 \pm 0.90$ & $2.39 \pm 0.63$ & $2.50 \pm 0.69$ & 0.604 \\
\hline Peritoneal $\mathrm{Kt} / \mathrm{N}$ & $1.75 \pm 0.55$ & $1.63 \pm 0.47$ & $1.64 \pm 0.55$ & 0.096 \\
\hline Inadequate dialysis dose & $18(15.1 \%)$ & $27(12.4 \%)$ & $4(7.8 \%)$ & 0.677 \\
\hline Albumin level (g/dL) & $3.59 \pm 0.48^{b}$ & $3.53 \pm 0.54^{b}$ & $3.05 \pm 0.61^{a}$ & $<0.001$ \\
\hline$\overline{\text { GNRI }}$ & $93.3 \pm 7.7^{b}$ & $93.1 \pm 8.42^{b}$ & $86.4 \pm 9.2^{\mathrm{a}}$ & $<0.001$ \\
\hline nPNA (g/kg/day) & $0.88 \pm 0.20$ & $0.89 \pm 0.18$ & $0.90 \pm 0.22$ & 0.900 \\
\hline MAP & $90 \pm 13$ & $92 \pm 12$ & $98 \pm 12$ & 0.080 \\
\hline Lean mass index $\left(\mathrm{kg} / \mathrm{m}^{2}\right)$ & $15.92 \pm 2.19^{a}$ & $16.53 \pm 1.99^{\mathrm{a}}$ & $17.91 \pm 2.64^{b}$ & $<0.001$ \\
\hline Fat mass index $\left(\mathrm{kg} / \mathrm{m}^{2}\right)$ & $5.23 \pm 2.30$ & $4.91 \pm 2.26$ & $4.78 \pm 2.34$ & 0.412 \\
\hline Urine volume (mL/day) & $700(200-2830)^{a}$ & $960(200-3300)^{b}$ & $1100(300-3700)^{b}$ & $<0.001$ \\
\hline $\operatorname{RRF}\left(\mathrm{mL} / \mathrm{min} / 1.73 \mathrm{~m}^{2}\right)$ & $2.90(0.33-34.30)^{a}$ & $3.49(0.58-15.46)^{a}$ & $4.22(1.50-23.41)^{b}$ & $<0.001$ \\
\hline Peritoneal albumin loss (mg/day) & $3479 \pm 1319^{a}$ & $3218 \pm 1273^{\mathrm{a}}$ & $2685 \pm 993^{b}$ & 0.001 \\
\hline Proteinuria level (mg/day) & $150(39-490)^{a}$ & $1241(504-3,458)^{b}$ & $5786(3,510-24,000)^{c}$ & $<0.001$ \\
\hline Glucose absorption (g/day) & $67.5 \pm 19.2$ & $65.4 \pm 21.9$ & $65.4 \pm 24.8$ & 0.676 \\
\hline \multicolumn{5}{|l|}{ At the end of follow-up } \\
\hline Creatinine $(\mathrm{mg} / \mathrm{dL})$ & $7.80 \pm 2.63^{a}$ & $8.50 \pm 2.96^{\mathrm{a}}$ & $10.43 \pm 3.35^{b}$ & $<0.001$ \\
\hline$\overline{\mathrm{CRP}}(\mathrm{mg} / \mathrm{dL})$ & $0.12(0.00-3.98)$ & $0.10(0.00-5.82)$ & $0.15(0.00-3.75)$ & 0.521 \\
\hline Weekly KtN & $2.33 \pm 0.69^{b}$ & $2.20 \pm 0.64^{a, b}$ & $2.01 \pm 0.50^{\mathrm{a}}$ & 0.026 \\
\hline Peritoneal Kt/N & $1.62 \pm 0.39$ & $1.55 \pm 0.39$ & $1.60 \pm 0.39$ & 0.326 \\
\hline Inadequate dialysis dose & $7(5.9 \%)$ & $31(14.2 \%)$ & $10(19.6 \%)$ & 0.058 \\
\hline Albumin (g/dL) & $3.80 \pm 0.47^{b}$ & $3.63 \pm 0.47^{a}$ & $3.59 \pm 0.48^{\mathrm{a}}$ & 0.008 \\
\hline GNRI & $97.2 \pm 7.2$ & $94.8 \pm 7.5$ & $94.9 \pm 7.3$ & 0.122 \\
\hline nPNA (g/kg/day) & $0.92 \pm 0.19$ & $0.94 \pm 0.22$ & $0.96 \pm 0.19$ & 0.641 \\
\hline$\overline{M A P}$ & $95 \pm 15^{a}$ & $96 \pm 13^{a}$ & $107 \pm 15^{b}$ & 0.006 \\
\hline Peritonitis rate (episodes/year) & $0.32 \pm 0.58$ & $0.34 \pm 0.58$ & $0.27 \pm 0.45$ & 0.720 \\
\hline Lean mass index $\left(\mathrm{kg} / \mathrm{m}^{2}\right)$ & $15.95 \pm 2.32^{\mathrm{a}}$ & $16.58 \pm 2.14^{a}$ & $18.03 \pm 2.10^{b}$ & $<0.001$ \\
\hline Fat mass index $\left(\mathrm{kg} / \mathrm{m}^{2}\right)$ & $5.73 \pm 2.32$ & $5.58 \pm 2.01$ & $5.41 \pm 2.30$ & 0.770 \\
\hline
\end{tabular}


Table 1 Comparison of the clinical characteristics according to the initial proteinuria level at the time of peritoneal dialysis (PD) initiation and the end of the follow-up period (Continued)

\begin{tabular}{|c|c|c|c|c|}
\hline Urine volume (mL/day) & $900(0-2480)^{b}$ & $810(0-2950)^{b}$ & $460(0-1600)^{a}$ & 0.001 \\
\hline $\mathrm{RRF}\left(\mathrm{mL} / \mathrm{min} / 1.73 \mathrm{~m}^{2}\right)$ & $3.11(0.00-24.3)^{b}$ & $2.88(0.00-17.26)^{b}$ & $1.41(0.00-6.14)^{a}$ & 0.008 \\
\hline Peritoneal albumin loss (mg/day) & $3028 \pm 1057$ & $3018 \pm 1200$ & $3174 \pm 1277$ & 0.606 \\
\hline Proteinuria level (mg/day) & $258(0-4000)^{a}$ & $636(0-4911)^{b}$ & $995(0-15600)^{b}$ & $<0.001$ \\
\hline
\end{tabular}

The data are expressed as numbers (percentages) for the categorical variables and median (range) or mean \pm standard deviation for the continuous variables. * Statistical significance was tested by one-way analysis of variance or Kruskal-Wallis test for the continuous variables and Pearson $x^{2}$ test or Fisher exact test for the categorical variables. The different superscripts $\left({ }^{a, b, c}\right)$ indicate significant differences from each other using post hoc Tukey comparison or Bonferroni correction.

DM, diabetes mellitus; CRP, C-reactive protein; APD, automated peritoneal dialysis; PET, peritoneal equilibration test; NA, non-available; GNRI, geriatric nutritional risk index; nPNA, normalized protein equivalent of nitrogen appearance; MAP, mean arterial pressure; RRF, residual renal function.

that in the other 2 groups. However, at the end of the follow-up period, there was no significant difference in GNRI among the 3 groups. The increases in GNRI and decreases in proteinuria levels or RRF in the $C$ group were greater than those in the other 2 groups $(P<0.001$; Table 2). At the time of $\mathrm{PD}$ initiation, the lean mass index in the $\mathrm{C}$ group was greater than that in the other 2 groups $(P<0.001)$. There was no significant difference in lean mass index change from the time of PD initiation to the end of the follow-up period. At the end of the follow-up period, weekly $K t / V$ in the $\mathrm{C}$ group was lower than that in the A group $(P=0.026)$. However, there was no significant difference in peritoneal $K t / V$ at either the time of PD initiation or the end of the follow-up period. Although the peritoneal albumin loss was less in the $C$ group than in the other groups at the time of PD initiation, no significant differences were observed in the peritoneal albumin loss at the end of follow-up period. There was no significant difference in change from the time of PD initiation to the end of the follow-up period.

Factors affecting GNRI and RRF decline

To identify the relevance of the variables affecting GNRI and RRF decline, clinical and laboratory parameters were analyzed using univariate and multivariate regression models (Table 3 and Table 4). The univariate and multivariate analyses revealed that age, DM, and proteinuria were negatively correlated with GNRI at the time of PD initiation. At the end of the follow-up period, age, DM, peritoneal albumin loss, proteinuria, and RRF were associated with GNRI. The initial RRF and proteinuria levels were negatively correlated with RRF decline during the follow-up. Notably, there was no significant association between RRF decline and MAP at PD initiation.

\section{Discussion}

This study demonstrates that a high proteinuria level is associated with malnutrition and rapid RRF or urine volume decline. A simultaneous decline in proteinuria level and RRF or urine volume appears to improve initial low GNRI. However, the RRF and urine volume decline led to decreased dialysis adequacy.

Proteinuria is a well-documented risk factor for the progression of chronic kidney disease in patients who are not treated with dialysis [16]. However, the specific effects of proteinuria level on RRF in patients on dialysis remain elusive. Jansen et al. showed that greater urinary protein loss is negatively associated with RRF [7]. However, using multivariate analysis, another study did not show that 24-hr proteinuria is associated with a faster

Table 2 Changes in the variables from the time of peritoneal dialysis initiation to the end of follow-up period: comparison of the $\mathbf{3}$ groups according to initial proteinuria levels

\begin{tabular}{|c|c|c|c|c|}
\hline & A group & B group & C group & $P$ value* \\
\hline Delta GNRI & $3.47 \pm 6.54^{\mathrm{a}}$ & $1.92 \pm 6.63^{\mathrm{a}}$ & $6.97 \pm 8.52^{b}$ & $<0.001$ \\
\hline Delta RRF $\left(\mathrm{mL} / \mathrm{min} / 1.73 \mathrm{~m}^{2}\right)$ & $0.00(-9.99 \text { to } 7.10)^{a}$ & $-0.81(-7.88 \text { to } 6.58)^{\mathrm{a}}$ & $-2.41(-23.41 \text { to } 2.31)^{b}$ & $<0.001$ \\
\hline Delta nPNA & $0.04 \pm 0.23$ & $0.05 \pm 0.23$ & $0.06 \pm 0.24$ & 0.898 \\
\hline Delta MAP & $4.4 \pm 16.3$ & $3.2 \pm 17.1$ & $8.6 \pm 15.4$ & 0.483 \\
\hline Delta total lean mass index & $0.47 \pm 1.19$ & $0.10 \pm 1.23$ & $-0.07 \pm 2.56$ & 0.198 \\
\hline Delta total fat mass index & $0.76 \pm 1.03$ & $0.75 \pm 1.87$ & $1.20 \pm 1.49$ & 0.418 \\
\hline Delta peritoneal albumin loss (mg/day) & $-233 \pm 995$ & $-59 \pm 1370$ & $324 \pm 1477$ & 0.075 \\
\hline Delta proteinuria (mg/day) & $197 \pm 648^{\mathrm{a}}$ & $-475 \pm 945^{a}$ & $-4626 \pm 5466^{b}$ & $<0.001$ \\
\hline
\end{tabular}

The data are expressed as numbers (percentages) for the categorical variables and median (range) or mean \pm standard deviation for the continuous variables. *Statistical significance was tested by one-way analysis of variance or Kruskal-Wallis test for the continuous variables and the Pearson $\mathrm{X}^{2}$ test or Fisher exact test for the categorical variables. The different superscripts $(a, b, c)$ indicate significant differences from each other using post hoc Tukey comparison or Bonferroni correction.

GNRI, geriatric nutritional risk index; RRF, residual renal function; nPNA, normalized protein equivalent of nitrogen appearance; MAP, mean arterial pressure. 
Table 3 Predictive factors affecting the Geriatric nutritional risk index at the time of peritoneal dialysis (PD) initiation and the end of the follow-up period

\begin{tabular}{|c|c|c|c|c|}
\hline \multirow[t]{2}{*}{ At the time of PD initiation } & \multicolumn{2}{|c|}{ Univariate } & \multicolumn{2}{|c|}{ Multivariate } \\
\hline & Standardized $\beta \pm \mathrm{SE}$ & $P$ value & Standardized $\beta \pm \mathrm{SE}$ & $P$ value \\
\hline Age (years) & $-0.142 \pm 0.033$ & 0.006 & $-0.115 \pm 0.032$ & 0.022 \\
\hline Use of icodextrin & $0.031 \pm 0.941$ & 0.552 & - & - \\
\hline Sex (female) & $0.014 \pm 0.889$ & 0.782 & - & - \\
\hline $\mathrm{DM}$ & $-0.265 \pm 0.852$ & $<0.001$ & $-0.185 \pm 0.882$ & $<0.001$ \\
\hline Peritoneal albumin loss (mg/day) & $-0.021 \pm 0.000$ & 0.683 & - & - \\
\hline $\operatorname{RRF}\left(\mathrm{mL} / \mathrm{min} / 1.73 \mathrm{~m}^{2}\right)$ & $0.051 \pm 0.150$ & 0.327 & - & - \\
\hline Proteinuria level (mg/day) & $-0.290 \pm 0.000$ & $<0.001$ & $-0.250 \pm 0.000$ & $<0.001$ \\
\hline \multicolumn{5}{|l|}{ At the end of follow-up } \\
\hline Age (years) & $-0.176 \pm 0.032$ & 0.003 & $-0.208 \pm 0.031$ & $<0.001$ \\
\hline Use of icodextrin & $0.062 \pm 0.906$ & 0.291 & - & - \\
\hline Sex (female) & $0.007 \pm 0.880$ & 0.899 & - & - \\
\hline $\mathrm{DM}$ & $-0.291 \pm 0.839$ & $<0.001$ & $-0.177 \pm 0.864$ & 0.003 \\
\hline Peritoneal albumin loss (mg/day)* & $-0.207 \pm 0.000$ & $<0.001$ & $-0.204 \pm 0.000$ & $<0.001$ \\
\hline $\operatorname{RRF}\left(\mathrm{mL} / \mathrm{min} / 1.73 \mathrm{~m}^{2}\right)^{*}$ & $0.189 \pm 0.151$ & 0.001 & $0.212 \pm 0.145$ & $<0.001$ \\
\hline Proteinuria level $(\mathrm{mg} / \text { day })^{*}$ & $-0.143 \pm 0.000$ & 0.016 & $-0.143 \pm 0.000$ & 0.014 \\
\hline
\end{tabular}

*The values are presented as findings at the end of the follow-up.

$\mathrm{SE}$, standard error; DM, diabetes mellitus; RRF, residual renal function.

RRF decline [17]. This study demonstrates that high proteinuria levels in patients on PD are associated with a rapid RRF decline. In this study, the RRF decline was $0.00(-9.99$ to 7.10$) \mathrm{mL} / \mathrm{min} / 1.73 \mathrm{~m}^{2}$ in the A group and $-0.81(-7.88$ to 6.58$) \mathrm{mL} / \mathrm{min} / 1.73 \mathrm{~m}^{2}$ in the B group; in contrast, it was -2.41 ( -23.41 to 2.31$) \mathrm{mL} / \mathrm{min} / 1.73 \mathrm{~m}^{2}$ in the $\mathrm{C}$ group. Although RRF decline occurred in the $\mathrm{B}$ and $C$ groups, the RRF in the patients with high proteinuria levels tended to show a steeper decline. The multivariate regression analysis showed similar results.

Malnutrition is associated with mortality and morbidity in patients on dialysis [18]. Hypoalbuminemia or protein energy wasting in PD patients is related to increased catabolism, decreased protein synthesis, and external protein loss from peritoneum or urine [18-20]. External protein loss can have an identical pathogenic effect on nephrotic syndrome [20]. The loss of peritoneal protein in PD patients averages $5 \mathrm{~g} /$ day [21,22]. One study demonstrated that peritoneal protein loss is related to mortality and malnutrition in patients on PD [20]. However, protein losses in the peritoneal effluent are usually compensated for by increased protein synthesis [23]. Balafa et al. showed that baseline peritoneal albumin and protein clearances are associated with comorbidities, but this is not a risk factor for decreased survival per se [22]. In the present study, the peritoneal albumin loss was less in the $\mathrm{C}$ group than in the A group at the time of PD initiation. High proteinuria levels are associated with hypoalbuminemia, which may be associated with decrease in peritoneal albumin loss. However, no

Table 4 Predictive factors affecting the decline in residual renal function (RRF) from the time of peritoneal dialysis initiation to the end of the follow-up period

\begin{tabular}{|c|c|c|c|c|}
\hline & \multicolumn{2}{|c|}{ Univariate } & \multicolumn{2}{|c|}{ Multivariate } \\
\hline & Standardized $\beta \pm S E$ & $P$ value & Standardized $\beta \pm \mathrm{SE}$ & $P$ value \\
\hline Age & $0.008 \pm 0.012$ & 0.897 & - & - \\
\hline Sex (female) & $0.122 \pm 0.321$ & 0.038 & $-0.064 \pm 0.278$ & 0.211 \\
\hline Use of icodextrin & $-0.092 \pm 0.333$ & 0.118 & - & - \\
\hline $\mathrm{DM}$ & $-0.096 \pm 0.321$ & 0.103 & - & - \\
\hline $\operatorname{MAP}(\mathrm{mmHg})^{*}$ & $0.087 \pm 0.018$ & 0.242 & & \\
\hline $\operatorname{RRF}\left(\mathrm{mL} / \mathrm{min} / 1.73 \mathrm{~m}^{2}\right)^{*}$ & $-0.517 \pm 0.045$ & $<0.001$ & $-0.505 \pm 0.045$ & $<0.001$ \\
\hline Peritoneal albumin loss (mg/day)* & $-0.117 \pm 0.000$ & 0.050 & - & - \\
\hline Proteinuria level $(\mathrm{mg} / \text { day })^{*}$ & $-0.315 \pm 0.000$ & $<0.001$ & $-0.271 \pm 0.000$ & $<0.001$ \\
\hline
\end{tabular}

* The values are presented as the findings at the time of peritoneal dialysis initiation.

$\mathrm{MAP}$, mean arterial pressure; DM, diabetes mellitus; $\mathrm{SE}$, standard error. 
significant difference was observed in peritoneal albumin loss among the 3 groups at the end of follow-up period. Compared with changes in proteinuria, those in peritoneal albumin loss were small (delta peritoneal albumin loss was $-233 \pm 995 \mathrm{mg} /$ day in A group, $-59 \pm 1370$ in B group, and $324 \pm 1477 \mathrm{mg} /$ day in C group). These data demonstrate the lack of a relationship between proteinuria and peritoneal albumin loss. In linear regression, the peritoneal albumin loss was negatively correlated with the nutritional status at the end of the follow-up period. Our data show that the initial nutritional status was associated with proteinuria alone, that follow-up nutritional status was associated with proteinuria and peritoneal albumin loss. High proteinuria levels may have a greater effect on nutritional status than peritoneal albumin loss.

The patients on PD who had high proteinuria levels showed rapid RRF decline and eventual improvement of nutritional status. The GNRI scores increased from $86.4 \pm$ 9.2 to $94.9 \pm 7.3$ in the $C$ group. The $C$ group demonstrated a significantly higher initial protein loss in the urine accompanied by malnutrition. However, the followup GNRI was not significantly different between the $\mathrm{C}$ group and the other 2 groups. The impact of the initial high proteinuria level on malnutrition was attenuated, along with a decreased RRF with increasing duration of PD. The change in the serum albumin level was similar to that in GNRI.

Preservation of RRF has been consistent independent predictor of survival in patients on PD [3-5,24]. The benefits include improved control of blood pressure and anemia, removal of uremic toxin, superior phosphate control, and dialysis adequacy [6]. Wang et al. showed that RRF preservation is associated with better nutritional status according to appetite improvement or the removal of inflammatory mediators [24]. However, uncontrolled high proteinuria levels are related to malnutrition. In fact, patients with uncontrolled high proteinuria levels who are not on dialysis could be treated with medical nephrectomy using iatrogenic nephrotoxic drugs. This study shows that RRF combined with heavy proteinuria is associated with malnutrition and that a rapid RRF decline leads to improved nutritional status. This study also shows that RRF declines lead to decreased dialysis adequacy. Because there were no significant differences in peritoneal $K t / V$ between the 3 groups at baseline or follow-up, the decline of the weekly $K t / V$ may be associated with the decreased renal clearance. However, there was no significant difference in number of patients with inadequate dialysis.

Previous studies have shown that RRF loss is associated with malnutrition in patients on PD [24-26]. However, these studies have limitations that differ from those of the present study. First, they had a cross- sectional design. Anuria or low RRF as a baseline characteristic was associated with poor nutritional status, but there are few data on the effects of RRF decline on nutrition. Second, patients were divided into groups according to RRF status. Patients with heavy proteinuria may be enrolled into groups along with patients with RRF. If patients with RRF were divided into groups with respect to proteinuria, subgroup analyses may show similar results. The present study had an observational design and simply monitored changes in RRF status. Patients with RRF were divided into 3 groups according to proteinuria status.

The patients with nephrotic syndrome and normal renal function have increased protein synthesis rates but inadequate responses to normalized serum albumin levels [27]. Patients on dialysis also experience increased protein synthesis in response to protein loss, but the response to protein loss in patients on dialysis is greater than that in patients with nephrotic syndrome and normal renal function [2,28]. Therefore, this malnutrition change may be more closely associated with increases in protein catabolic rate than renal function. The present study did not show whether the nutritional improvement in patients on PD with nephrotic-range proteinuria levels is associated with changes in protein catabolic rate or decreases in proteinuria levels. Further investigations are needed to determine the definite association between improved nutrition and RRF decline or decreased proteinuria levels.

In the present study, MAP was not associated with a decline in RRF, and at the end of the follow-up period, MAP in $C$ group was higher than that in the other groups. Previous studies have shown that MAP in the post-dialysis period is not associated with a decline in RRF in patients on PD $[29,30]$. However, diastolic blood pressure at predialysis period is related to decline in RRF [7]. The relation between blood pressure and RRF remains controversial. The higher MAP observed in $\mathrm{C}$ group at the end of follow-up period may be associated with rapid decline in RRF or underlying disease (high incidence of DM in the C group). In our cohort, MAP at the end of the follow-up period was $102 \pm 14 \mathrm{mmHg}$ in patients with $\mathrm{RRF}<1 \mathrm{~mL} / \mathrm{min} / 1.73 \mathrm{~m}^{2}$ and $97 \pm 12 \mathrm{mmHg}$ in those with $\mathrm{RRF} \geq 1 \mathrm{~mL} / \mathrm{min} / 1.73 \mathrm{~m}^{2}(P=0.020)$. The RAS blockade is a well-known therapeutic target associated with RRF preservation [6]. Most patients in the present study received a RAS blockade, and we were unable to analyze the association between RAS blockade use and RRF decline.

It is important to evaluate whether aminoglycoside use is associated with RRF decline in patients on PD. Some previous studies have shown variable results regarding the association between aminoglycoside use and rapid RRF decline [17,31,32]. A multicenter study recently 
revealed that empiric treatment with aminoglycoside for peritonitis was not associated with a rapid RRF decline [33]. In present study, all patients with peritonitis received aminoglycoside as first-line antibiotics. There was no significant difference in peritonitis rate or aminoglycoside use among the 3 groups. Investigations that enroll only patients with peritonitis are needed to determine the effect of aminoglycoside on RRF decline.

Serum albumin is not the gold standard of nutrition in patients on PD [34]. Serum albumin is greatly influenced by variable factors such as malnutrition, hydration status, and inflammation. This variable is included in the GNRI equation. Therefore, it is difficult to consider GNRI as a reliable measure of nutrition in patients with heavy proteinuria levels. At the time of PD initiation, the differences in GNRI among the 3 groups may be not associated with nutritional status. The present study shows data for nPNA, lean mass index, and fat mass index using DEXA. The lean mass index in the $\mathrm{C}$ group was greater than that in the other 2 groups at the time of PD initiation and the end of the follow-up period. However, there was no significant difference in lean mass index change from the time of PD initiation to the end of the follow-up period. However, because overhydration causes overestimation of lean mass by DEXA, the initial lean mass levels in $C$ group may have been overestimated. Therefore, the increases in lean mass in $\mathrm{C}$ group may be higher than those in the other groups. There was no significant difference in fat mass index among the 3 groups, but we did detect a greater increase in fat mass index in the $\mathrm{C}$ group (delta fat mass index: of $0.76 \pm 1.03,0.75 \pm 1.87$, and $1.20 \pm 1.49$ in the A, B, and $C$ groups, respectively). The same trend was seen in nPNA.

\section{Conclusion}

The high proteinruia level at PD initiation was associated with rapid RRF decline. The attenuation of the nephrotic proteinuria, along with the RRF decline, was associated with the improvement of the malnutrition.

\section{Competing interests}

No competing interests to declare.

\section{Authors' contributions}

SHK designed research, performed, and wrote the paper. JWP and KHC interpreted the data. KYW contributed to acquisition of data. JYD was involved in revising the manuscript critically for important intellectual content and have given final approval of the version to be published. All authors read and approved the final manuscript.

\section{Acknowledgements}

The authors have no acknowledgements to make. No funding was received for this study.

Received: 21 September 2012 Accepted: 27 November 2012

Published: 17 December 2012

\section{References}

1. Palmer BF: Proteinuria as a therapeutic target in patients with chronic kidney disease. Am J Nephrol 2007, 27:287-93.

2. Kaysen GA: Biological basis of hypoalbuminemia in ESRD. J Am Soc Nephrol 1998, 9:2368-76.

3. Bargman JM, Thorpe KE, Churchill DN: Relative contribution of residual renal function and peritoneal clearance to adequacy of dialysis: a reanalysis of the CANUSA study. J Am Soc Nephrol 2001, 12:2158-62.

4. Paniagua $R$, Amato $D$, Vonesh $E$, et al: ADEMEX, a prospective, randomized, controlled trial. J Am Soc Nephrol 2002, 13:1307-20.

5. Termorshuizen F, Korevaar JC, Dekker FW, van Manen JG, Boeschoten EW, Krediet RT: The relative importance of residual renal function compared with peritoneal clearance for patient survival and quality of life: an analysis of the Netherlands Cooperative Study on the Adequacy of Dialysis (NECOSAD)-2. Am J Kidney Dis 2003, 41:1293-302.

6. Marrón B, Remón C, Pérez-Fontán M, Quirós P, Ortíz A: Benefits of preserving residual renal function in peritoneal dialysis. Kidney Int Suppl 2008, 108:S42-51.

7. Jansen MA, Hart AA, Korevarr JC, Dekker FW, Boeschoten EW, Krediet RT: NECOSAD Study Group. Predictors of the rate of residual renal function in incident dialysis patients. Kidney Int 2002, 62:1046-53.

8. Mujais S, Nolph K, Gokal R, et al: Evaluation and management of ultrafiltration problems in peritoneal dialysis International Society for Peritoneal Dialysis Ad Hoc Committee on Ultrafiltration Management in Peritoneal Dialysis. Perit Dial Int 2000, 20(suppl 4):S5-21.

9. Watson PE, Watson IE, Bratt RD: Total body water volumes for adult males and females estimated from simple anthropometric measurements. Am J Clin Nutr 1980, 33:27-39.

10. Bergstrom J, Heimburger $O$, Lindholm B: Calculation of the protein equivalent of total nitrogen appearance from urea appearance: what formulas should be used. Perit Dial Int 1998, 18:467-73.

11. Lorenz FH: Der Konstitutionsindex der Frau. Klin Wochenshr 1929, 16:734-6.

12. National Kidney Foundation: K/DOQI clinical practice guidelines for bone metabolism and disease in chronic kidney disease. Am J Kidney Dis 2003, 42(S1):201

13. Bouillanne O, Morineau G, Dupont C, et al: Geriatric Nutritional Risk Index: a new index for evaluating at-risk elderly medical patients. Am J Clin Nutr 2005, 82:777-83.

14. Kobayashi I, Ishimura E, Kato Y, et al: Geriatric nutritional risk index, a simplified nutritional screening index, is a significant predictor of mortality in chronic dialysis patients. Nephrol Dial Transplant 2010, 25:3361-5.

15. Yamada K, Furuya $R$, Takita $T$, et al: Simplified nutritional screening tools for patients on maintenance hemodialysis. Am J Clin Nutr 2008, 87:106-13.

16. Peterson JC, Adler S, Burkart JM, et al: Blood pressure control, proteinuria and the progression of renal disease, The Modification of Diet in Renal Disease Study. Ann Intern Med 1995, 123:754-62.

17. Singhal MK, Bhaskaran S, Vidgen E, Bargman JM, Vas SI, Oreopoulos DG: Rate of decline of residual renal function in patients on continuous peritoneal dialysis and factors affecting it. Perit Dial Int 2000, 20:429-38.

18. Stenvinkel $P$, Heimbürger $O$, Lindholm B, Kaysen GA, Bergström J: Are there two types of malnutrition in chronic renal failure? evidence for relationships between malnutrition, inflammation and atherosclerosis (MIA syndrome). Nephrol Dial Transplant 2000, 15:953-60.

19. Combe C, McCullough KP, Asano Y, Ginsberg N, Maroni BJ, Pifer TB: Kindey Disease Outcomes Quality Initiative (K/DOQI) and the Dialysis Outcomes and Practice Patterns Study (DOPPS): nutrition guidelines, indicators, and practices. Am J Kidney Dis 2004, 44:\$39-46.

20. Heaf JG, Sarac S, Afzal S: A high peritoneal large pore fluid flux causes hypoalbuminaemia and is a risk factor for death in peritoneal dialysis patients. Nephrol Dial Transplant 2005, 20:2194-201.

21. Krediet RT, Zuyderhoudt FM, Boeschoten EW, Arisz L: Peritoneal permeability to proteins in diabetic and non-diabetic continuous ambulatory peritoneal dialysis patients. Nephron 1986, 42:133-40.

22. Balafa O, Halbesma N, Struijk DG, Dekker FW, Krediet RT: Peritoneal albumin and protein losses do not predict outcome in peritoneal dialysis patients. Clin J Am Soc Nephrol 2011, 6:561-6.

23. Prinsen $B H$, Rabelink TJ, Beutler JJ, et al: Increased albumin and fibrinogen synthesis rate in patients with chronic renal failure. Kidney Int 2003, 64:1495-504. 
24. Wang AY, Sea MM, Ip R, et al: Independent effects of residual renal function and dialysis adequacy on actual dietary protein, calorie, and other nutrient intake in patients on continuous ambulatory peritoneal dialysis. J Am Soc Nephrol 2001, 12:2450-7.

25. Szeto CC, Lai KN, Wong TY, Law MC, Leung CB, Yu AW, Li PK: Independent effects of residual renal function and dialysis adequacy on nutritional status and patient outcome in continuous ambulatory peritoneal dialysis. Am J Kidney Dis 1999, 34:1056-64.

26. Wang AY, Woo J, Wang M, Sea MM, Sanderson JE, Lui SF, Li PK: Important differentiation of factors that predict outcome in peritoneal dialysis patients with different degrees of residual renal function. Nephrol Dial Transplant 2005, 20:396-403.

27. Kaysen GA, Gambertoglio J, Jiminez I, Jones H, Hutchison FN: Effect of dietary protein intake on albumin homeostasis in nephrotic syndrome. Kidney Int 1986, 29:572-7.

28. Kaysen GA, Schoenfeld PY: Albumin homeostasis in patients undergoing continuous peritoneal dialysis. Kidney Int 1984, 25:107-14.

29. Moist LM, Port FK, Orzol SM, Young EW, Ostbye T, Wolfe RA, HulbertSheraton T, Jones CA, Bloembergen WE: Predictors of loss of residual renal function among new dialysis patients. J Am Soc Nephrol 2000, 11:556-64.

30. Johnson DW, Mudge DW, Sturtevant JM, Hawley CM, Campbell SB, Isbel NM, Hollett P: Predictors of decline of residual renal function in new peritoneal dialysis patients. Perit Dial Int 2003, 23:276-83.

31. Shemin D, Maaz D, St Pierre D, Kahn SI, Chazan JA: Effect of aminoglycoside use on residual renal function in peritoneal dialysis patients. Am J Kidney Dis 1999, 34:14-20.

32. Baker RJ, Senior H, Clemenger M, Brown EA: Empirical aminoglycosides for peritonitis do not affect residual renal function. Am J Kidney Dis 2003, 41:670-5.

33. Badve SV, Hawley CM, McDonald SP, Brown FG, Boudville NC, Wiggins K, Bannister KM, Johnson DW: Use of aminoglycosides for peritoneal dialysis-associated peritonitis does not affect residual renal function. Nephrol Dial Transplant 2012, 27:381-7.

34. Jones CH, Newstead CG, Will EJ, Smye SW, Davison AM: Assessment of nutritional status in CAPD patients: serum albumin is not a useful measure. Nephrol Dial Transplant 1997, 12:1406-13.

doi:10.1186/1471-2369-13-171

Cite this article as: Kang et al:: Impact of heavy proteinuria on clinical outcomes in patients on incident peritoneal dialysis. BMC Nephrology 2012 13:171

\section{Submit your next manuscript to BioMed Central and take full advantage of:}

- Convenient online submission

- Thorough peer review

- No space constraints or color figure charges

- Immediate publication on acceptance

- Inclusion in PubMed, CAS, Scopus and Google Scholar

- Research which is freely available for redistribution 